\title{
Lanthanum associated abnormal liver function tests in two patients on dialysis: a case report
}

\author{
Girish Namagondlu ${ }^{1}$, Norman Main ${ }^{1}$, Lucy Yates ${ }^{1}$, Joanne Mooney ${ }^{1}$, \\ Sangita Sathyamurthy ${ }^{1}$, Indiver Daryanani ${ }^{1}$, Alex Crowe ${ }^{1}$, Tom Ledson ${ }^{1,2}$ and \\ Anindya Banerjee*1,2
}

\author{
Address: ${ }^{1}$ Department of Nephrology, Arrowe Park University Teaching Hospital NHS Foundation Trust, UK and ${ }^{2}$ Department of Nephrology, \\ Countess of Chester NHS Foundation Trust, UK \\ Email: Girish Namagondlu - drgirish@hotmail.co.uk; Norman Main - norman.main@whnt.nhs.uk; Lucy Yates - lucy.yates@whnt.nhs.uk; \\ Joanne Mooney - jaonne.mooney@whnt.nhs.uk; Sangita Sathyamurthy - sangita.sathyamurthy@whnt.nhs.uk; \\ Indiver Daryanani - indiver.daryanani@whnt.nhs.uk; Alex Crowe - alex.crowe@nhs.net; Tom Ledson - thomas.ledson@coch.nhs.uk; \\ Anindya Banerjee* - anindya.banerjee@coch.nhs.uk \\ * Corresponding author
}

Published: 9 December 2009

Journal of Medical Case Reports 2009, 3:9321 doi:10.1 186/1752-1947-3-9321
Received: 4 November 2008

Accepted: 9 December 2009

This article is available from: http://www.jmedicalcasereports.com/content/3/1/932I

(C) 2009 Namagondlu et al; licensee BioMed Central Ltd.

This is an Open Access article distributed under the terms of the Creative Commons Attribution License (http://creativecommons.org/licenses/by/2.0), which permits unrestricted use, distribution, and reproduction in any medium, provided the original work is properly cited.

\begin{abstract}
Lanthanum (La) is a phosphate binder used in patients on dialysis in the UK. As it has only recently been in use, there are no long-term data about safety of this rare metal in human subjects with renal failure on renal replacement therapy. La has not been previously reported to cause any adverse reactions apart from nausea, sickness, dialysis graft occlusion and abdominal pain. We report here La induced abnormal liver function tests in a male and a female patient of 70 and 44 years old each, on peritoneal dialysis (PD) and haemodialysis (HD) respectively, the first report of such an adverse reaction to this agent.
\end{abstract}

\section{Introduction}

Chronic kidney disease (CKD) is accompanied by disorders in bone and mineral metabolism, with effects on cardiovascular function and patient survival. In late stages of $\mathrm{CKD}$, dietary modification is insufficient to control serum phosphate levels. Consequently, pharmacological therapy with an oral phosphate-binding agent is required to reduce the absorption of ingested phosphate.

A recent calcium and aluminium free phosphate binding agent approved for use in the UK is a metal based phosphate binder, Lanthanum carbonate [1]. La is a rare-earth trace metal that naturally occurs in monazite sand and coal and is a trivalent cation that acts as a calcium channel blocker $[2,3]$.
We report here two cases of oral La induced abnormal liver function tests in patients on dialysis. To the best of our knowledge this is the first such report showing a possible association between oral La and abnormal liver function tests in patients on dialysis.

\section{Case Reports \\ Case I}

A 70-year-old Caucasian man with end stage renal failure (ESRF) secondary to hypertensive nephrosclerosis on PD for one year presented with a one-day history of lower abdominal pain in November 2007. There was no history of altered bowel habits or features of sepsis. There were no other co-morbidities or any history of alcohol abuse or use of recreational drugs. His dialysis adequacy was 
reported as a Kt/V of 2.2/week, blood pressure (BP) was well controlled at $135 / 75 \mathrm{mmHg}$ and residual urine output was about $0.7 \mathrm{l} /$ day.

On examination he looked clinically well. His abdomen was soft without any other physical signs of any note.

His medication included Allopurinol, Atorvastatin, Sodium Valproate, Aspirin, Alphacalcidol, Omeprazole, Irbesartan, laxatives and Aranesp. La was added as a firstline phosphate binder about 2 weeks prior to admission at $750 \mathrm{mg}$ thrice daily, the recommended starting dose of this binder instead of Sevelamer which he was taking at $2.4 \mathrm{~g}$ thrice daily. The rest of his medication had remained unchanged for several years.

He had a normal full blood count (FBC), bilirubin 16 micromol/L (normal 3-17 $\mu \mathrm{mol} / \mathrm{L}$ ), alkaline phosphatase (ALP) 574 IU/L (normal 40-129 iu/L), alanine transaminase (ALT) 301 IU/L (normal 8-45 iu/L), gammaglutamyl transferase (GGT) 185 IU/L (normal 8-50 iu/L). Ferritin was 236 microgram/L (normal 22-322 $\mu \mathrm{g} / \mathrm{L}$ ) and C-reactive protein (CRP) was $2 \mathrm{mg} / \mathrm{L}$ (normal 1-10 mg/L). Routine liver function tests four weeks previously were normal with bilirubin $9 \mathrm{mmol} / \mathrm{L}$, ALP $90 \mathrm{iu} / \mathrm{L}$, ALT $9 \mathrm{iu} / \mathrm{L}$, GGT 7 iu/L. Peritoneal fluid appeared clear. Gram staining and peritoneal fluid cultures were negative. His clotting parameters were normal.

A liver virology screen including hepatitis A, B, C was negative. Epstein - Barr virus (EBV) and cytomegalovirus (CMV) serology were negative. An ultrasound scan of his liver was reported as normal liver parenchyma texture. There was no evidence of gall-bladder calculi. An abdominal X-ray revealed some evidence of faecal overload and the pain was felt related to constipation. Treatment with additional laxatives had good effect.

La was stopped and Sevelamer restarted. His LFTs started improving within a week and were back to normal within 4 weeks of stopping La and blood results from December
2007 showed a bilirubin of $1 \mathrm{mmol} / \mathrm{L}$, ALP $87 \mathrm{iu} / \mathrm{L}, \mathrm{GGT}$ $16 \mathrm{iu} / \mathrm{L}$, ALT $21 \mathrm{iu} / \mathrm{L}$. Table 1 summarizes his blood test results.

\section{Case 2}

A 44 year old patient on HD presented with fluid overload in February 2008. She was diagnosed to have coronary artery disease which needed stenting during this admission.

She had ESRF from Type 1 diabetes diagnosed in 1988 and other diabetes associated complications. She also had mild mitral regurgitation and a history of cholecystectomy from gallstones. She never had good diabetes control and before commencing on renal replacement treatment in 2007 via PD her average HbA1C were about $11.5 \%$. As she continued to have problems with nephrotic range proteinuria from poorly controlled diabetes with consequent fluid overload, she was switched to HD in December 2007. Following commencement of HD her fluid balance improved, blood pressure medications were minimized and her diabetes control improved significantly with an HbA1C 9.5\% in February 2008. She did not drink alcohol or abuse recreational drugs. Her admission Kt/V was 1.6; her BP was 140/80 mmHg and her residual urine output was $1.5 \mathrm{l}$ /day. Interdialytic weight gains ranged from 2-3 $\mathrm{kg}$ at each session.

Her medication list included Sevelamar, Alfacalcidol, Irbesartan, Citalopram, Quinine Sulphate, Bisoprolol, Levemir, Novorapid, Lansoprazole and Aspirin. Her admission phosphates were elevated at over $2 \mathrm{mmol} / \mathrm{L}$ (normal 0.8-1.4 mmol/L), hence in place of Sevelamer, $\mathrm{La}$ was started in March 2008 at a dose of $750 \mathrm{mg}$ thrice daily. Her LFTs before admission were normal (bilirubin 8 mmol/L, ALT $19 \mathrm{iu} / \mathrm{L}$, ALP $97 \mathrm{iu} / \mathrm{L}$ and GGT $22 \mathrm{iu} / \mathrm{L})$. Ferritin and CRP were respectively $236 \mathrm{microgram} / \mathrm{L}$ and 6 mg/L. By April 2008 her ALP was $602 \mathrm{iu} / \mathrm{L}$, GGT $699 \mathrm{iu} / \mathrm{L}$ and ALT $75 \mathrm{iu} / \mathrm{L}$; a Gastroenterology review was sought at this point and a subsequent liver ultrasound scan was reported as normal.

Table I: Biochemical test results for Case I during December 2007 before and after Lanthanum was commenced and withdrawn (oral lanthanum started on 0I.II.2007 and stopped on 10.1 I.07).

\begin{tabular}{llllll}
\hline & $\begin{array}{l}\text { Bilirubin } \\
\text { Micromol/I }\end{array}$ & $\begin{array}{l}\text { ALP } \\
\text { IU/L }\end{array}$ & $\begin{array}{l}\text { ALT } \\
\text { IU/L }\end{array}$ & $\begin{array}{l}\text { Gamma GT } \\
\text { IU/L }\end{array}$ & $\begin{array}{l}\text { Albumin } \\
\text { g/L }\end{array}$ \\
\hline Normal & $05-21$ & $40-125$ & $0-40$ & $10-50$ & $36-52$ \\
$\mathbf{0 3 . 1 0 . 0 7}$ & 09 & 90 & 09 & 07 & 34 \\
$\mathbf{0 8 . 1 1 . 0 7}$ & 16 & 574 & 301 & 185 & 37 \\
$\mathbf{1 5 . 1 1 . 0 7}$ & 15 & 420 & 74 & 109 & 33 \\
$\mathbf{1 9 . 1 1 . 0 7}$ & 16 & 284 & 29 & 67 & 33 \\
$\mathbf{2 2 . 1 1 . 0 7}$ & 13 & 205 & 21 & 51 & 29 \\
$\mathbf{2 2 . 1 2 . 0 7}$ & 01 & 87 & 12 & 16 & 24 \\
\hline
\end{tabular}

ALP-Alkaline phosphatase, ALT-Alanine Transaminase, GammaGT-Gamma -glutamyl transpeptidase 
Later in April 2008 during a routine HD clinic at a satellite dialysis unit she complained of incessant itching. Routine bloods confirmed jaundice with bilirubin $49 \mathrm{mmol} / \mathrm{L}$ with further derangement of other liver enzymes (ALT 89 $\mathrm{iu} / \mathrm{L}$, ALP $1006 \mathrm{iu} / \mathrm{L}$, GGT $748 \mathrm{iu} / \mathrm{L}$ ). Liver virology screen was negative and EBV and CMV serology were negative. Clotting parameters were normal.

As La was the only new agent started this was stopped and Renagel restarted. By the first week of May 2008 her bilirubin May 2008 her bilirubin was $14 \mathrm{mmol} / \mathrm{L}$, ALT 43 $\mathrm{iu} / \mathrm{L}, \mathrm{ALP} 665 \mathrm{iu} / \mathrm{L}$ and GGT $404 \mathrm{iu} / \mathrm{L}$. Table 2 summarizes her blood test results.

\section{Discussion}

To the best of our knowledge this is the first report of abnormal LFTs' in association with La in patients receiving dialysis.

Abnormalities of liver function tests in patients on chronic dialysis can be related to a variety of causes ranging from viral infection, congestion from fluid overload and drugs. Indeed necropsy findings of the hepatobiliary system from 78 patients with ESRD maintained on HD have shown $90 \%$ exhibited some form of an abnormality, such as congestion complicated by fibrosis, fatty metamorphosis, triaditis, hemosiderosis, and cystic changes along with chronic active hepatitis; almost 22\% showed cholelithiasis [4]. Reports of electron microscopy examination of hepatic tissue mention marked proliferation of smooth endoplasmic reticulum in addition to alteration of mitochondria and rough endoplasmic reticulum and an increase in cytoplasmic lipid droplets [5].

The reported side effects in patients given La compared to patients given placebo for 4-6 weeks were nausea, vomiting, dialysis graft occlusion, and abdominal pain [6]. It is thought that as La transits through the liver via a trans-cellular pathway this organ is probably well protected against damage. In the liver La is mainly found in the lysosomes and biliary canaliculi. Although in clinical trials there was no difference in LFTs' between patients receiving
La versus standard therapy [7], La does however accumulate in bone, gastrointestinal tract and liver of people and animals given this drug, particularly in CKD; in animal models of CKD this is from increased absorption [8], and in humans both the extent and the rate of absorption is greater than in individuals with normal kidney function [9]. This persistent accumulation and poor clearance of $\mathrm{La}$ once it enters tissues indicates that La has a long biological half-life with the potential to act as a cumulative toxin. Organ burden cannot be monitored by blood La levels [10]. Previous studies have shown trivalent cations to be causal in membrane rigidification processes [11] with changes in enzyme activity in chicken livers even at exceedingly low concentrations [12].

Neither of our cases demonstrated hepatic synthetic functional derangement as clotting parameters was within normal limits. Ferritin levels in both patients were within acceptable range and there was no evidence of an intercurrent sepsis to explain an abnormality in the LFTs. Both cases demonstrated biochemical cholestasis along with hepatocyte injury which promptly resolved on La withdrawal. This is particularly significant as both our cases were on the minimum recommended dose of this binder, the maximum dose recommended in patients with poor phosphate control being $4.5 \mathrm{~g}$ daily.

Average urine output and fluid balance were reasonable for both cases, hence we do not suspect fluid overload with liver congestion to be the cause of abnormal LFTs. Even if congestion or poor diabetes control were to be responsible for abnormal LFTs in Case 2, the prompt reversal of her jaundice once La was stopped indicates an association with this agent.

All renal failure patients are on a multitude of medications and our patients were not any different. Although some of these such as Sodium Valproate, Atorvastatin or even Omeprazole as in Case 1 and Lansoprazole in Case 2 could contribute to a biochemical picture of abnormal LFTs, the time course of events in our cases would seem to suggest otherwise, particularly as these patients had been

Table 2: Biochemical test results for Case 2 during March/April 2008 before and after Lanthanum was commenced and withdrawn (oral lanthanum started on $23^{\text {rd }}$ March 2008 and stopped on $23^{\text {rd }}$ April 2008).

\begin{tabular}{llllll}
\hline & $\begin{array}{l}\text { Bilirubin } \\
\text { Micromol/I }\end{array}$ & $\begin{array}{l}\text { ALP } \\
\text { IU/L }\end{array}$ & $\begin{array}{l}\text { ALT } \\
\text { IU/L }\end{array}$ & $\begin{array}{l}\text { Gamma GT } \\
\text { IU/L }\end{array}$ & $\begin{array}{l}\text { Albumin } \\
\text { g/L }\end{array}$ \\
\hline Normal & $05-21$ & $40-125$ & $0-40$ & $10-50$ & $36-52$ \\
$\mathbf{2 3 . 0 1 . 0 8}$ & 07 & 115 & 38 & 22 & 37 \\
$\mathbf{2 3 . 0 3 . 0 8}$ & 08 & 125 & 35 & 45 & 36 \\
$\mathbf{1 7 . 0 4 . 0 8}$ & 49 & 1006 & 89 & 748 & 31 \\
$\mathbf{0 1 . 0 5 . 0 8}$ & 14 & 665 & 43 & 404 & 31 \\
$\mathbf{0 5 . 0 6 . 0 8}$ & 07 & 205 & 35 & 87 & 32 \\
\hline
\end{tabular}

ALP-Alkaline phosphatase, ALT-Alanine Transaminase, GammaGT-Gamma -glutamyl transpeptidase 
on these agents for a number of years. La was the only new change to their prescription within about 2 weeks prior to presentation.

Re-challenging with La was felt unnecessary as alternative phosphate binding agents were available. As Case 2 was jaundiced this action may have had potentiated the hepato-toxic effect of La.

We did not have liver biopsy confirmation of lanthanum deposition or serum lanthanum levels and this is a potential shortcoming of our report. Serum La levels are not available easily; liver biopsy would have helped however the patients improved following withdrawal of La thus obviating a need for this invasive procedure. Additionally, both our patients had significant residual urine output in addition to adequate dialysis clearances. One can therefore speculate cumulative accumulation of La over only a few weeks of La use subsequently leading to La related hepatotoxicity is less likely in such a setting and that the abnormalities described could well be explained by chance alone; however 2 cases with a similar time scale of events should at least indicate that such an association is possible, whether from drug hepatotoxicity or an idiosyncratic reaction.

\section{Conclusion}

The time course of events in this report seems to suggest a pharmacological hepatotoxic/cholestatic effect in association with La in 2 patients on dialysis; this paper however does not conclusively demonstrate La toxicity in patients on dialysis. Physicians should at least be alert to this feature of $\mathrm{La}$ as a possible complication. We suspect other long-term side-effects of La in human subjects on dialysis also require further investigation, particularly in view of its pharmacokinetics in CKD.

Recommendations and guidelines about La and the dosage it should be used at, can only then become clearer

\section{Consent}

Written informed consent was obtained from the patient for publication of this case report. A copy of the written consent is available for review by the Editor-in-Chief of this journal.

\section{Competing interests}

The authors declare that they have no competing interests.

\section{Authors' contributions}

$\mathrm{AB}$ and $\mathrm{AC}$ conceived of the study; GN and NM drafted the manuscript. LY, JM, SS, ID and TL participated in its design and carried out the coordination. All authors read and approved the final manuscript.

\section{References}

I. D'Haese PC, Spasovski GB, Sikole A, Hutchison A, Freemont T], Sulkova S, Swanepoel C, Pejanovic S, Djukanovic L, Balducci A, Coen G, Sulowicz W, Ferreira A, Torres A, Curic S, Popovic M, Dimkovic N, De Broe ME: A multicenter study on the effects of lanthanum carbonate (Fosrenol) and calcium carbonate on renal bone disease in dialysis patients. Kidney Int Supp/ 2003, 63:S73-S78.

2. Palmer RJ, Butenhoff JL, Stevens JB: Cytotoxicity of the rare earth metals cerium, lanthanum, and neodymium in vitro: comparisons with cadmium in a pulmonary macrophage primary culture system. Environ Res 1987, 43:142-I56.

3. Hu X, Ding Z, Chen Y, Wang X, Dai L: Bioaccumulation of lanthanum and cerium and their effects on the growth of wheat (Triticum aestivum L.) seedlings. Chemosphere 2002, 48:62I-629.

4. Pahl MV, Vaziri ND, Dure-Smith B, Miller R, Mirahmadi MK: Hepatobiliary pathology in hemodialysis patients: an autopsy study of 78 cases. Am J Gastroenterol I 986, 8I (9):783-7.

5. Kawata S, Seki K, Minami Y, Kameda Y, Nishikawa M, Tarui S, Yoshitake S, Nishiuchi M, Oda T: Morphological changes of the liver in uremic patients treated with chronic hemodialysis--laparoscopic observations and light- and electron-microscopic studies. Gastroenterol Jpn 1980, 15(3):2।2-20.

6. Shire Pharmaceuticals Ltd. Hampshire, UK: Fosrenal (lanthanum carbonate) Prescribing Information.

7. Finn WF, Joy MS, Webster I, et al.: A long-term (2-year) assessment of the safety and efficacy of lanthanum carbonate, a non-calcium, non-aluminum phosphate binder, for the treatment of hyperphosphatemia. Program and abstracts of the 40th ERA-EDTA World Congress of Nephrology; June 8-I2, 2003; Berlin, Germany .

8. Lacour B, Lucas A, Auchere D, Ruellan N, de Serre Patey NM, Drueke TB: Chronic renal failure is associated with increased tissue deposition of lanthanum after 28-day oral administration. Kidney Int 2005, 67:1062-1069.

9. Sack M: Fosrenol (lanthanum carbonate) is well-tolerated in patients requiring hemodialysis: Results of a Phase I clinical trial. American Society of Nephrology Annual Meeting 2002; Philadelphia, PA, Nov I-4, 2002.

10. Drüeke TB: Lanthanum carbonate as a first-line phosphate binder: the "cons". Semin Dial 2007, 20(4):329-32.

II. Verstraetena SV, Nogueirab LV, Schreierb S, Oteizaa PI: Effect of Trivalent Metal lons on Phase Separation and Membrane Lipid Packing: Role in Lipid Peroxidation. Archives of Biochemistry and Biophysics 1997, 338:121-127.

12. Wu Y: Lanthanide ions inhibit the activity of dihydrofolate reductase from chicken liver. Biometals 2000, 13:195-20I.

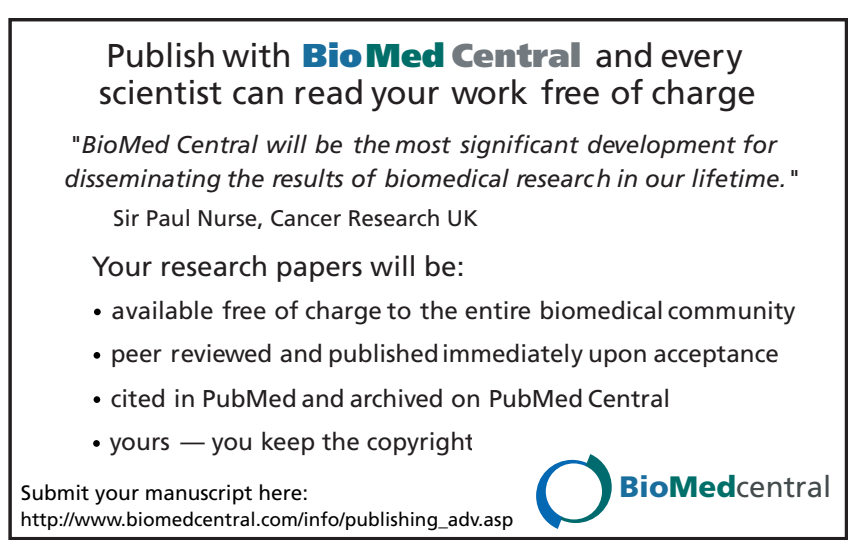

